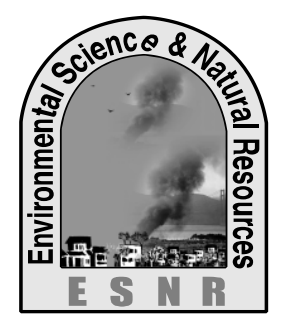

\title{
Impacts of Brick Fields on Environment and Social Economy at Bagatipara, Natore, Bangladesh
}

\author{
M. F. Jerin ${ }^{1 *}$, S. K. Mondol ${ }^{1}$, B. C. Sarker ${ }^{2}$, R. H. Rimi ${ }^{1}$ and S. Aktar ${ }^{2}$ \\ ${ }^{1}$ Department of Environmental Science and Resource Management, Mawlana Bhashani Science and \\ Technology University, Tangail-1902, Bangladesh \\ ${ }^{2}$ Department of Environmental Science, Bangladesh Agricultural University, \\ Mymensingh-2202, Bangladesh \\ *Corresponding author: fa1pinu@gmail.com
}

\begin{abstract}
This study investigated environmental and socio-economic impacts of brick fields at Bagatipara upazila of Natore district, Bangladesh. A questionnaire survey was conducted at selected community members living at or near brick field areas with aim to assess impacts of brick fields on air, water, soil, vegetation as well as socio-economic conditions. Findings of this study were based on randomly selected respondents' perception on change of any resource or condition. Crop loss, decreased soil fertility and subsequent reductions in crop production were reported. Trees around brickfields were dusted badly and water quality of nearby water bodies deteriorated because of emerged dust and ash from brick fields. Noticeable negative impacts on aquaculture were found. Except few, majority of the respondents were suffering from various diseases like eye irritation, skin diseases and respiratory problems. Despite creating work opportunities for local people, brick fields of the study area adversely affected environment and social economy.
\end{abstract}

Key words: Agriculture, Aquaculture, Brickfields, Environmental Pollution and Socio-Economic Impact

\section{Introduction}

\section{Background}

Bricks play significant role as a construction material. In Bangladesh about 8,000 brick fields are set up without clear environmental guidelines (The Financial Express, 2013). About 25 to 26 percent of country's wood is used for burning bricks every year, causing deforestation. Usually brickfields in Bangladesh are located near towns or major construction sites (Banglapedia, 2009). But according to the Brick Kiln Control (amended) Act-2001, "there must be no establishment of brick kilns within a three-kilometer radius of human inhabitation or reserved forest" (The Daily Star, 2014).

Brick burning contributes to environmental pollution, ecosystem damage and also to absorption of greenhouse gases in the atmosphere in higher quantities (IUSS, 2002). Brick kilns have long term and short-term impacts on the environment. Hampering normal vegetation process, reducing crop production, deforestation etc. are short term effects while long-term impacts include ozone layer depletion, global warming, production of photochemical smog, reduction in land fertility, etc. (Pokhrel, 2011). Once top soil is removed for making bricks, it takes 25 to 30 years for those lands to regain fertility. On average, each kiln burns 350 tones of woods per year, so more active kilns cause rapid deforestation. Black smoke from brick kilns moves away the species which are involved in pollination process, in turn declines agricultural production (Islam and Rahman, 2011).

Besides, brickfield workers are forced to accept a subhuman life because of polluted air and poor water quality. Exposure to such high levels of pollutants can jeopardize immunity of human body, contributing to respiratory disorders like lung cancer, asthma, chronic bronchitis, and emphysema (Joshi and Dudani, 2008). The most severe health impacts of outdoor air pollution are associated with particulate matter (size $>10$ microns) (Raut, 2003), which is commonly found in brick kilns. Exposure to higher temperatures, higher dust density and particulate matter over a long time result in occupational health problems, including serious disease (e.g. lung cancer (Begum et al., 2010).

Tiny airborne particles or aerosols those are less than a hundred micrometers are collectively referred to as total suspended particulate matter (TSP) (EPA, 2012). Most of the brick kilns in Bangladesh are poorly designed, which causes incomplete combustion of coals (Ahmed, 2007). This incomplete combustion produces carbon monoxide $(\mathrm{CO})$, which increases risk for heart diseases. If rubber tires are used as fuel then along with $\mathrm{CO}$, emission from brick kilns comprises of fine dust particles, hydrocarbons, sulphur dioxide $\left(\mathrm{SO}_{2}\right)$, oxides of nitrogen (NOx), fluoride compounds and small amount of carcinogenic dioxins (Joshi and Dudani, 2008; WHO, 2013). Fuel type for brickfields mainly depends on its availability. Typical brick kilns use wood, recycled motor oil, coal, diesel, rubber tire, trash, and plastics as fuel. However, all types of fuel are responsible for the emission of toxic gases. Brick kilns are one of the major sources of air pollution in Bangladesh (Guttikunda, 2009). About 33\% of brick kilns illegally use firewood to burn bricks due to unavailability of coal. To meet the demand, a large number of trees are cut down; causing significant deforestation. Firewood accounts for nearly 25 percent of fuel used in brick kilns in Bangladesh every year. Many brick manufacturers set up kilns near forests with intention to exploit forests illegally (IPS, 2001).

The study aimed to reveal changes in socioeconomic and environmental aspects what the respondents observed before and after establishment of brickfields around them. Resulting information was expected to indicate positive or negative impacts of the brickfields on agriculture, aquaculture and socioeconomic condition of the study area. 


\section{Materials and Methods}

\section{Study Area}

Bagatipara is located at $24.3306^{\circ} \mathrm{N}$ and $88.944^{\circ} \mathrm{E}$ with an area of $139.37 \mathrm{~km}^{2}$. The main occupation of this area is agriculture comprising $40.04 \%$ among all occupation types. The land use pattern is characterized by single, double and triple crop which covers $34 \%, 42 \%$ and $24 \%$, respectively, where cultivable land under irrigation is $34 \%$. The cultivable land is 11,000 hectares and fallow land is 243 hectares (Community Report, 2012). Fig. 1 shows the location of the brick kilns in Bagatipara (red triangles), around which the study work was conducted.

\section{Data collection}

Primary data were collected by a questionnaire survey on local people. For the questionnaire survey, a total of 107 people were selected randomly at the study area. However, all respondents were later divided in two groups (i) the owner and workers of brickfields in category-1 consisting of a total 57 respondents and (ii) the affected people living around the brickfields in category- 2 consisting of a total 50 respondents. By field observation, total six brickfields were found in the study area and so the survey was conducted in and around these brickfields.

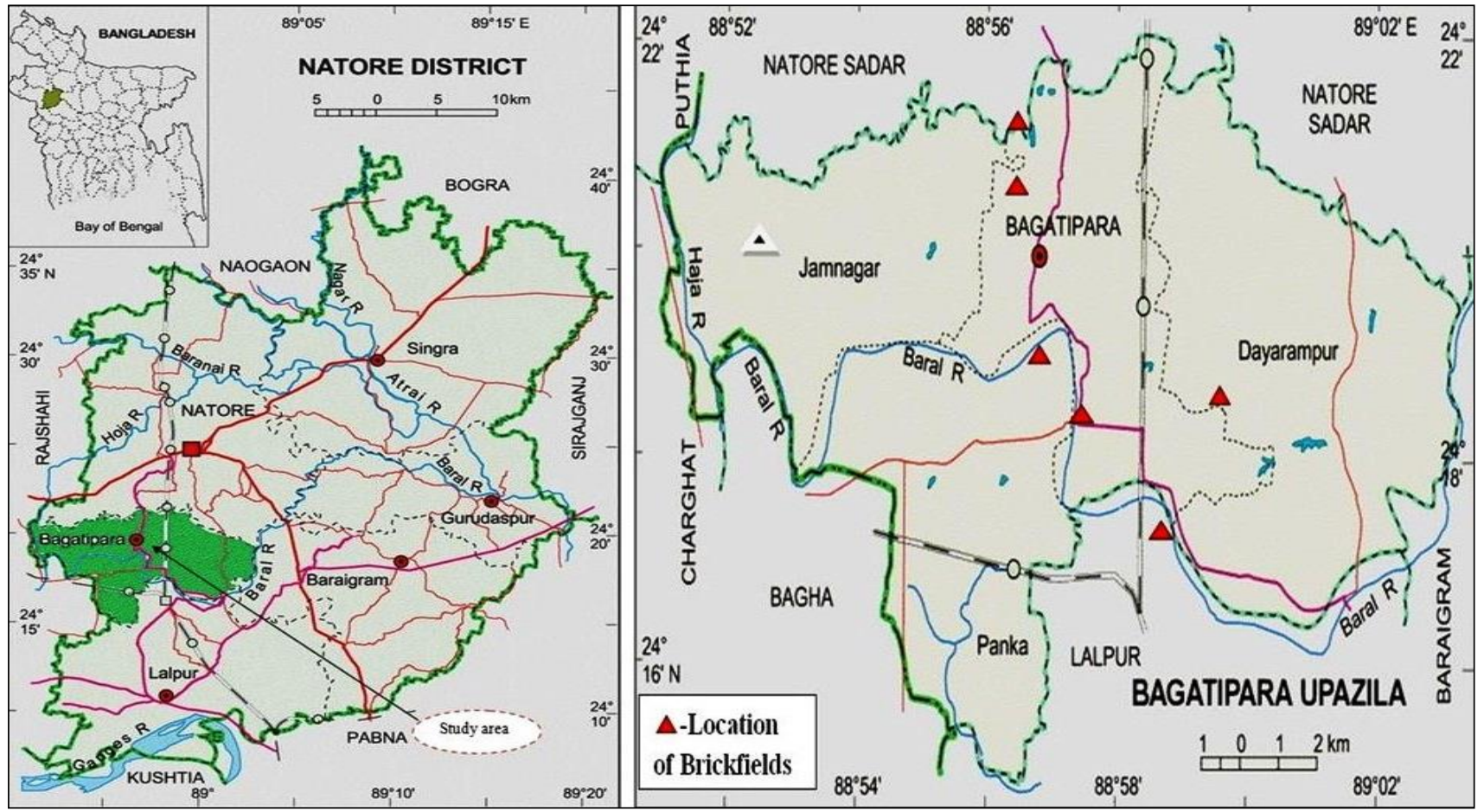

Fig. 1. Map of the study area (Modified from Banglapedia, 2009).

The socio-economic impacts of brickfield on a participant were assessed in terms of his/her occupation, income, health and housing conditions. Environmental impacts of brickfield were assessed in terms of changes in soil fertility, agricultural production, vegetation, fish production, air quality and water quality on the basis of how respondents found these after construction of brick kilns. Secondary data and information for this study were collected from relevant books, daily national newspapers, journals and websites.

\section{Data processing and analysis}

Collected data were analyzed by SPSS (Statistical Package for Social Science) software and later plotted using Microsoft Office Excel.

\section{Results and Discussion}

\section{Socio-economic impacts of brickfield}

Respondents from category-1 were engaged in brick molding, burning, and transportation and were most vulnerable to health hazards because of direct involvement with brickfield activities. They worked for economic benefit without considering its adverse impacts, while respondents from category-2 were engaged in various occupations like farming, aquaculture and household activities (Fig. 2). But they were also affected due to close proximity to the brickfields.

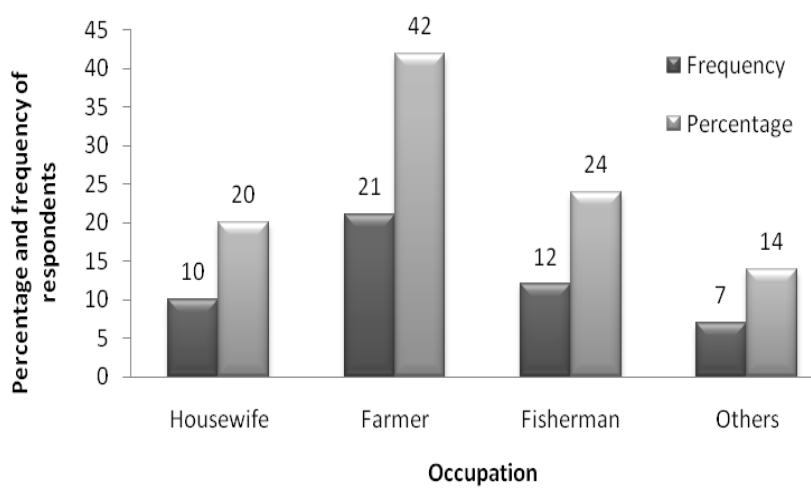

Fig. 2. Occupation types of category-2 respondents. 


\section{Income level of respondents}

All respondents who worked in brickfields were found to be economically benefited. Most of them were of medium income range 5000-7500 BDT (46\%), although this amount of wage is not fairly adequate for standard living (Community Report, 2012). They considered this as a chance to have better life because brickfields created permanent job opportunities locally which were not available previously. $36 \%$ of the respondents were engaged with other works and were of lower income range (2500-5000 BDT).
Health status of respondents

Majority of the respondents in category-1were found suffering from severe health problems $(62 \%)$, relatively less respondents were suffering minor health problems $(30 \%)$ and the rest $8 \%$ got no health problem as shown in Table 1. The study revealed that, among the respondents of category-2 (local inhabitants), most people suffered from respiratory diseases (35\%), followed by eye irritation (33\%) and skin disease (12\%), however $20 \%$ of them were not affected by any disease.

Table 1. Types of disease found incategory-1 respondents

\begin{tabular}{lc}
\hline Types of diseases & Percentage of affected respondents \\
\hline Skin disease & 12 \\
Eye irritation & 12 \\
Respiratory problems & 10 \\
Skin disease and Eye irritation & 10 \\
Skin disease and respiratory diseases & 12 \\
Eye Irritation and respiratory diseases & 12 \\
No problem & 08 \\
Total & 100 \\
\hline
\end{tabular}

\section{Structure of housing}

Various types of housing structures were observed in the study area. Among observed 100 houses, $16 \%$ of the houses were built of tin with concrete floor and $14 \%$ of houses with tin shed building. A few portions of houses, $11 \%$ were built by tin with earthen floor and $5 \%$ were single storied concrete building. This kind of housing structure indicated that despite being involved with brick production they did not afford to use it as building material.

\section{Environmental Impacts of Brickfield}

\section{Effects on soil fertility}

Majority of the respondents (83\%) opined that brickfield had major effect on soil fertility as well as agricultural production. The respondents who owned agricultural lands near brick fields were negatively affected by black smoke and ash that spread over the crop. On the other hand, $16 \%$ of the respondents complained about minor effect and $10 \%$ of respondents felt no impact on soil fertility. The Upazila Agricultural Office also reported that crop production has reduced adjacent to the brickfield area in recent years. Burning of soil decreases soil $\mathrm{pH}$, increase sand and decrease clay content (Glaser et al., 2002). It has serious impacts on physical, biological, and chemical properties of soil resulting sharp declination in soil fertility and productivity (Khan et al., 2007; Thapa, 2011).

\section{Effect on agricultural production}

A few respondents $21 \%$ opined that, there were no effects of brickfields on agricultural production. Majority of the respondents $79 \%$ alleged emission of black smoke for reduction in agricultural production. Some farmers also emphasized on the fact that some of the adjacent lands were fertile arable land where all kinds of crops and vegetables could grew only few years ago. But after brick kiln was set up near that crop field; production of crops had been declined. During survey, we could observe directly that many of the agricultural lands had become unsuitable for producing any crops due to over exploitation of its top soil. Farmers in this area have already experienced the problems of drying water sources, low water holding capacity on soils, poor crop stability and reduced crop productivity. To recover the level of production, farmers are now applying high doses chemical fertilizers, which have harmful consequences to ecological system.

\section{Effect on vegetation}

Majority of the respondents $(85 \%)$ told that agricultural productions were decreasing with time and brick field had major effect (lower production, poor development, different diseases etc.) on vegetation [fruits and vegetables] and $9 \%$ of the respondents commented that brickfield had minor effects on vegetation and $6 \%$ respondents were not aware of any adverse effects on vegetation. The respondents $(45 \%)$ who were owner of brickfields did not confess effects of brickfields on vegetation alleged by the farmers. However, $30 \%$ of them confessed some major effects; saying that flowering and fruiting trees were affected only.

\section{Effect on aquaculture}

More than half $(58 \%)$ of the respondents in category-2 said that, "brickfield has major effect on fish production and aquatic plant production" and rest of the respondents reported minor effects on aquaculture. Water pollution of nearby water bodies hampered production of fish and vegetables. The respondents who owned pond near the brick fields reported that fish 
production declined after setting up brickfields in that area.

\section{Air pollution}

Air pollution was visible in the study area due to emissions and dusts form brick fields. In some residential areas trees were found their leaves covered with dusts coming from the brick fields. Many people in those areas suffered from various respiratory diseases due to acute air pollution.

\section{Conclusions}

From the study it was found that most of the brickfields of the study area were located near agricultural lands and residential areas those were responsible for loss of agricultural production, fish cultivation and local community's health problems in great extent. Besides, brick fields were considered as the principle reason of top soil degradation and environmental pollution of the area.

\section{Acknowledgement}

Authors would like to thank local government authorities of Bagatipara Upazila Agricultural Office, Natore, Bangladesh for providing information during research work.

\section{References}

Ahmed, S. 2007. Modeling of Ambient Air Pollution in a Cluster of Brickfields, M.Sc. Engineering Thesis. 2007. Bangladesh University of Engineering and Technology, Dhaka, Bangladesh.

Banglapedia. 2009. National Encyclopedia of Bangladesh, Asiatic Society of Bangladesh.

Begum, B. A.; Biswas, S. K. and Hopke, P. K. 2010. Key Issues in Controlling Air in Dhaka, Atmospheric Environment, 45(40): 7705-7713.

Community Report Natore Zila. 2012. Population and Housing Census 2011, Bangladesh Bureau of Statistics, Statistics and Informatics Division, Ministry of Planning, Bangladesh, 41-63 pp.

EPA (Environmental Protection Agency). 2012. What are the six common air pollutants? [Retrieved from www.epa.gov/air/urbanair on 2 July, 2014]

Glaser, B.; Lehmann, J. and Zech, W. 2002. Ameliorating physical and chemical properties of highly weathered soils in the tropics with charcoal-a review. Biology and fertility of soils, 35(4): 219230.

Guttikunda, S. 2009. Impact analysis of brick kilns on the air quality in Dhaka, Bangladesh. SIM-Air Working Paper Series, p. 234.

IPS. 2001. Environment-Bangladesh: Brick Kilns Threaten Forest and Health. [Retrieved from: http://www.goo.gl/okJUCi on 12 August, 2016]

Islam, M. A. and Rahman, M. M. 2011. Effects of brickfields on agriculture at Madhupurupazila in Tangail district, MS thesis, Department of Environmental Science and Resource Management, Mawlana Bhashani Science and technology university, Tangail, Bangladesh.
International Union Soil Science (IUSS). 2002. Soil and the environment, IUSS Commission VIII. World Cong of Soil Science, International Union Soil Science, Thailand, p. 66.

Joshi, S. K. and Dudani, I. 2008. Environmental Health Effects of Brick Kilns in Kathmandu Valley, Kathmandu University Medical Journal, 6(21): 11.

Khan, H. R.; Rahman, K.; Abdur Rouf, A. J. M.; Sattar, G. S.; Oki, Y. and Adachi, T. 2007. Assessment of degradation of agricultural soils arising from brick burning in selected soil profiles. International Journal Environmental Science and Technology, 4(4): 471- 480.

Pokhrel, R. and Lee, H. 2011. Strategy for the Air Quality Management for Brick Kiln Industries in Nepal, Society for Nepalese students in Korea, p. 456

Raut, A. K. 2003. Brick Kilns in Kathmandu Valley: Current status, environmental impacts and future options, Himalayan Journal of Science, 1(1): 59-61.

Thapa, S. 2011. In Kathmandu Valley, there are more than 500 brick kilns. Brick Kilns: A Threat to Urban Agriculture in Kathmandu, Nepal. [Retrieved from www.cityfarmer.info/2011/08/22/brick-kilns-athreat-to-urban-agriculture-in-kathmandu-Nepal on 23 December, 2014]

The Daily Star. 2014. Brick kilns near reserve forest defying laws. [Retrieved from: www.thedailystar.net/brick-kilns-near-reserveforest-defying-laws-16667 on 23 December, 2014]

The Financial Express. 2013. Brickfields and the threats to environment [Retrieved from: www.goo.gl/ PvzFAEon 23 December, 2014]

WHO (World Health Organization). 2013. Air Pollution. [Retrieved from: www.goo.gl/KTywNQ on 23 December, 2015]. 